\title{
Article \\ Study on Seismic Isolation of Long Span Double Deck Steel Truss Continuous Girder Bridge
}

\author{
Yongjian Chen ${ }^{1, *}$, Honglie Sun ${ }^{1}$ and Zhenfa Feng ${ }^{2}$ \\ 1 College of Civil Engineering, Fuzhou University, Fuzhou 350116, China; n190520060@fzu.edu.cn \\ 2 China Construction Fifth Engineering Division Corp., Ltd., Changsha 410019, China; \\ fengzhenfa@hnsxtjzgcwwgc999.onexmail.com \\ * Correspondence: chenyongjian@fzu.edu.cn
}

Citation: Chen, Y.; Sun, H.; Feng, Z. Study on Seismic Isolation of Long Span Double Deck Steel Truss Continuous Girder Bridge. Appl. Sci. 2022, 12, 2567. https://doi.org/ $10.3390 /$ app 12052567

Academic Editor: Mario D’Aniello

Received: 20 September 2021

Accepted: 18 October 2021

Published: 1 March 2022

Publisher's Note: MDPI stays neutral with regard to jurisdictional claims in published maps and institutional affiliations.

Copyright: (C) 2022 by the authors. Licensee MDPI, Basel, Switzerland. This article is an open access article distributed under the terms and conditions of the Creative Commons Attribution (CC BY) license (https:// creativecommons.org/licenses/by/ $4.0 /)$.

\begin{abstract}
In order to improve the seismic performance of long-span double deck steel truss continuous girder bridge, taking Dao Qing Chau Bridge in Fuzhou as an engineering background, the isolation scheme of friction pendulum bearing (FPB) and friction pendulum bearing combined with viscous dampers is applied to study seismic performance. A three-dimensional dynamic model of the bridge is established using SAP2000. Taking three artificial seismic waves as seismic excitation, the seismic response of the seismic structure is calculated by nonlinear time history integration, and is then compared with the seismic response of the seismic reduction and isolation structure. The results show that the friction pendulum bearing (FPB) scheme and combined seismic dissipation and isolation (CSDI) scheme show a good seismic dissipation and isolation effect and ensure the safety of the bridge structure. However, for whole-bridge isolation, friction pendulum bearing (FPB) will produce certain residual deformations and additional stress of the bearing under the conditions of temperature and external load. For the purpose of protecting the bearing, it is recommended to use the combined seismic dissipation and isolation (CSDI) scheme.
\end{abstract}

Keywords: double deck steel truss; continuous girder bridge; friction pendulum bearing; viscous damper; combined seismic dissipation and isolation

\section{Introduction}

Earthquakes are a kind of natural disaster with sudden and strong damages. Under the actions of rare earthquakes, even a building's structure can collapse, which threatens the safety of human beings [1-3]. The emergence of double deck bridges in recent years has eased urban traffic to a certain extent, but consequent seismic problems that follow are thought-provoking. During the Loma Prieta earthquake in 1989 [4-6], the double deck viaduct structure in San Francisco, USA, the upper supporting column of the bridge broke and fell onto the lower deck, and the lower deck had excessive lateral displacement under the earthquake action, which caused it to collide with the supporting column and it suffered shear failure. Therefore, in the process of double-layer bridge design, the following problems need to kept in mind: (1) the vertical support columns of upper and lower deck should be able to cope with large deformation, which means to design using ductile components; (2) paying attention to the relative displacement of the upper and lower deck joints to avoid shear failure; and (3) the upper and lower deck beams and joints should be designed according to the capacity protection.

It was found that, when the damping of a structure is stable and the natural vibration period of the structure exceeds a certain limit, the seismic response of a structure will decrease with an extension in the natural vibration period. When a natural vibration period is stable, the seismic response decreases with the increase in damping. Therefore, in the design of structural seismic dissipation and isolation, we can design according to these two basic rules: (1) by prolonging the natural vibration period and (2) structural damping 
increases. Taking a long-span cable-stayed bridge as the engineering background, Li et al. established two seismic isolation systems: friction pendulum bearing (FPB) of fixed pier and damping spherical bearing of fixed pier [7]. Calvi et al. analyzed the change in the axial force of a bridge structure after using friction pendulum bearing (FPB) compared to seismic structure [8]. Rabiei et al. applied friction pendulum bearing (FPB) to structural seismic isolation design, analyzed the vertical seismic action of the structure, and deduced the motion equation of the bearing using the Newmark- $\beta$ method [9]. In addition, there are many scholars and experts who have explored and discovered facts about the performance of viscous dampers. Agrawal et al. introduced the characteristics of viscous damper [10]. Through theoretical analysis, it has been pointed out that the main factors affecting the performance of dampers are the damping coefficient and damping index. Ahmadizadeh studied the optimization of the layout position of a damper, and the influence of the damping coefficient and damping index [11]. Wong and Kevin studied a nonlinear damper and optimized the parameters of the damper [12].

Seismic control of engineering structure is to change and adjust the dynamic characteristics of the structure by installing some isolation devices (such as isolation bearings), some energy dissipation mechanisms (such as dampers), some additional substructure (such as tuned mass dampers [13-17]), or to exert external forces, so as to limit the dynamic response of an engineering structure under the action of an earthquake within an allowable range, in order to ensure the safety, serviceability, and durability of the engineering structure [18-22].

Based on the characteristics of a double deck steel truss continuous girder bridge, to ensure that the structure is in a safe state under the action of an earthquake, this paper studies the scheme of friction pendulum bearing (FPB) and the scheme of a combined use of friction pendulum bearing and viscous dampers, which are a kind of combined seismic dissipation and isolation (CSDI) bearing.

\section{Structural Finite Element Model}

\subsection{Double Deck Steel Truss Bridge}

The main bridge of the Dao Qing Chau Bridge, which crosses a river adopts, the scheme is a double-deck steel truss continuous girder bridge with a span of $121+276+121$ meters. The standard section of the main bridge adopts a two-way six-lane road with a width of $31 \mathrm{~m}$; the distance between the rail transit lines is $4.2 \mathrm{~m}$, which means that there is two-way traffic. The layout of main span is shown in Figure 1. A cross section of the main bridge is shown in Figures 2-4. A dynamic analysis model of the bridge is established by using the finite element software, SAP2000. We replace the first pier with "0\# pier", and second pier with "1\# pier" and so on, as shown in Figure 5 . The steel truss structure, piers, beams, and piles are simulated using the beam elements; the concrete bridge deck is simulated using plate elements; and the bearing system is simulated using the elastic elements. The Finite element model of piers can be seen in Figure 6.

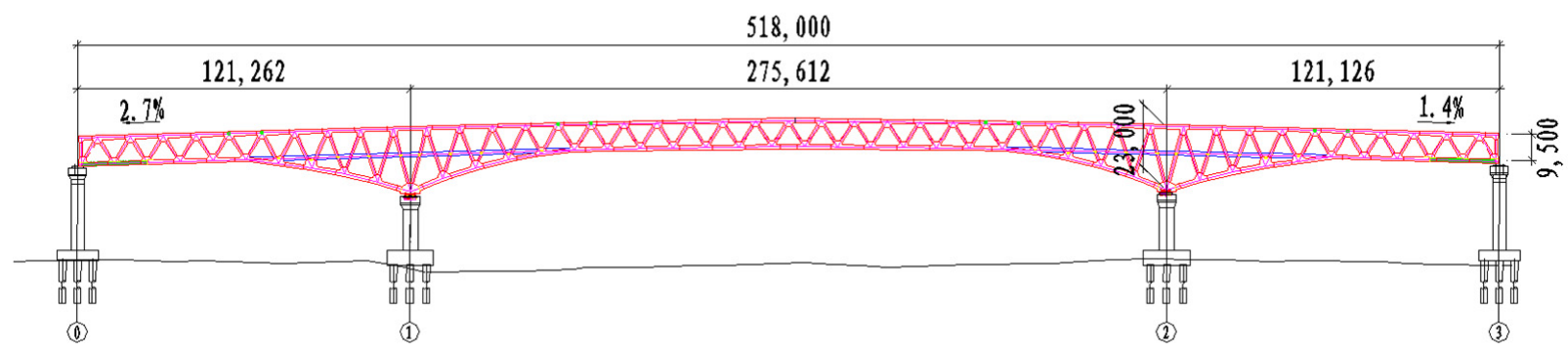

Figure 1. The layout of main span (Unit: mm). 


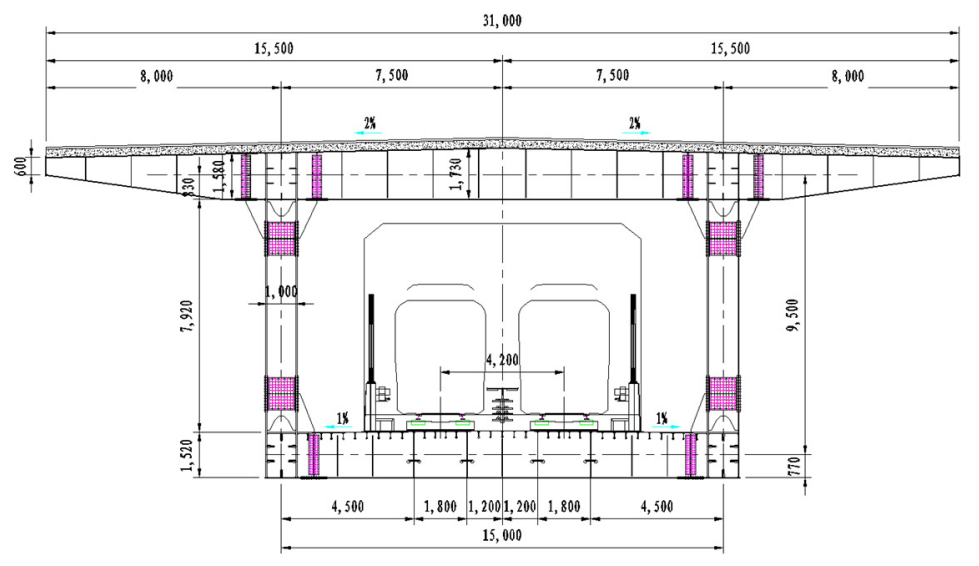

Figure 2. Mid-span cross section of main bridge (Unit: mm).

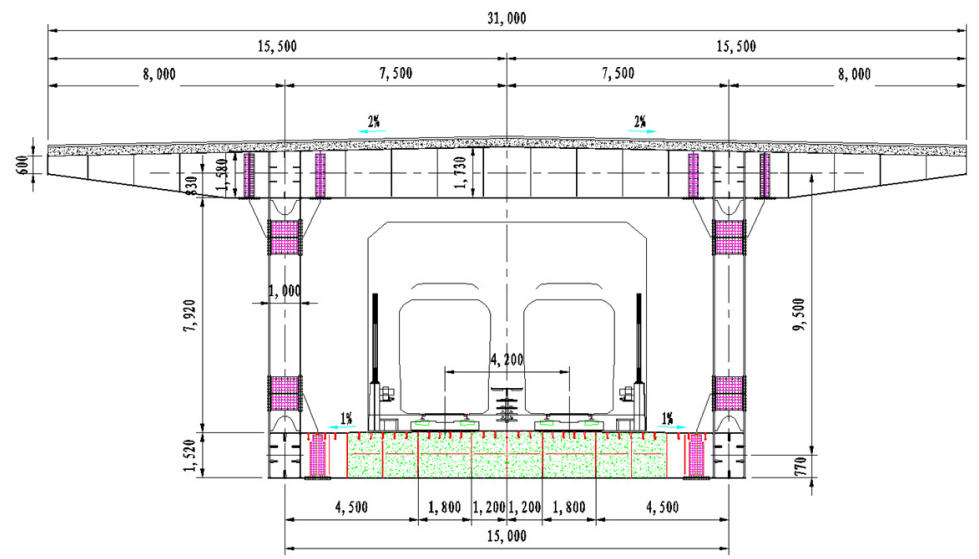

Figure 3. Cross section of ballast segment (Unit: $\mathrm{mm}$ ).

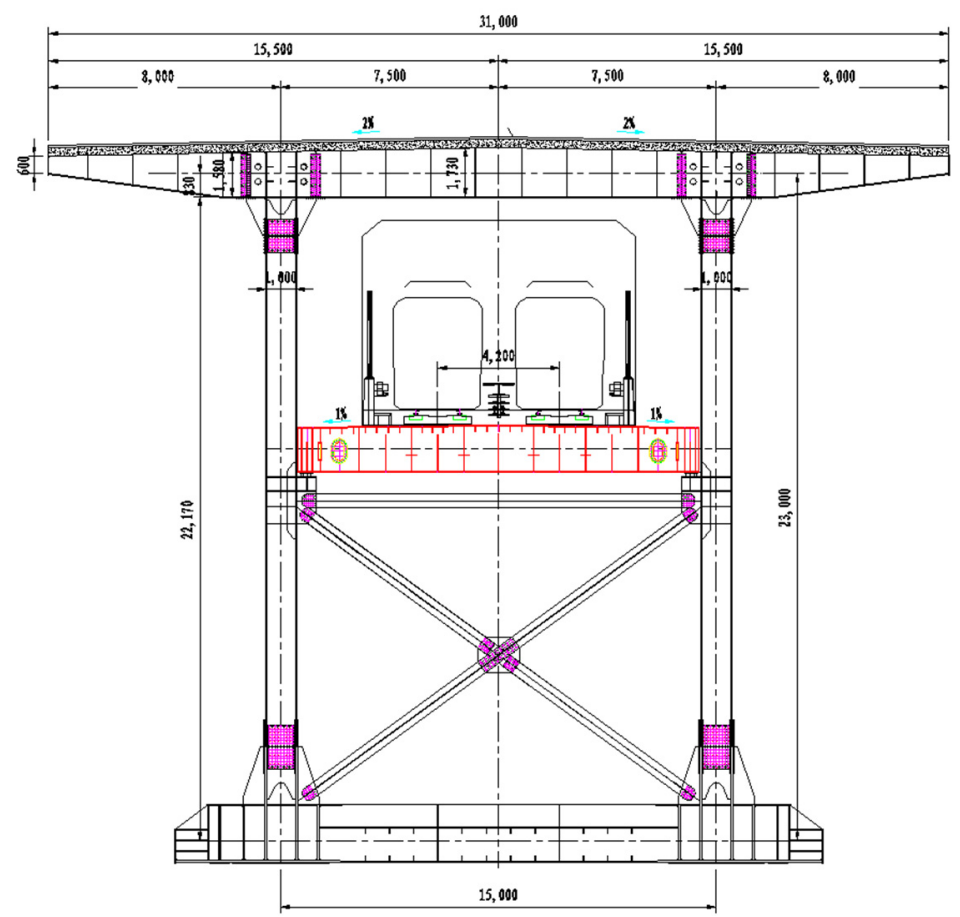

Figure 4. Cross section at bearing (Unit: $\mathrm{mm}$ ). 


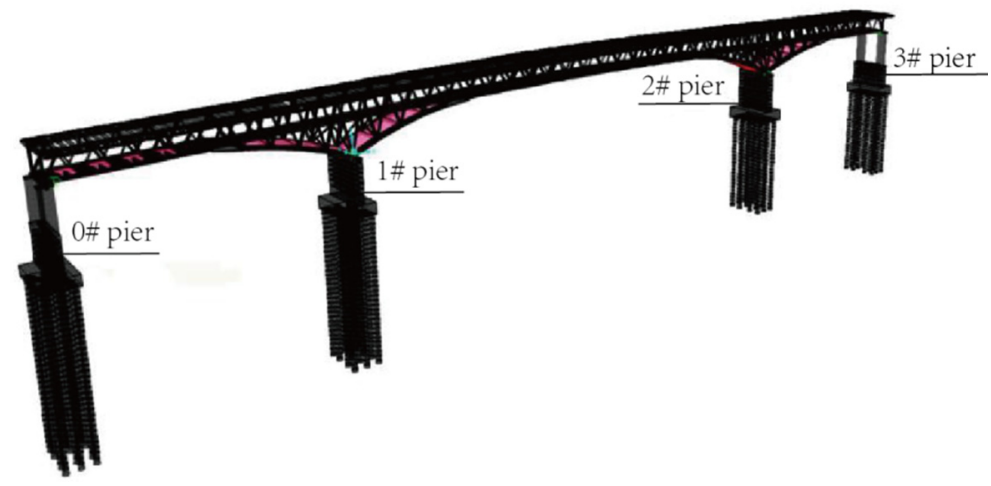

Figure 5. Finite element model of double-deck bridge.

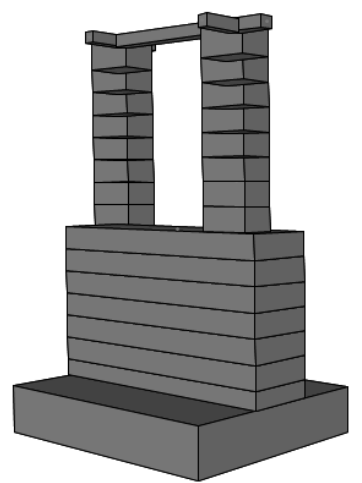

(a)

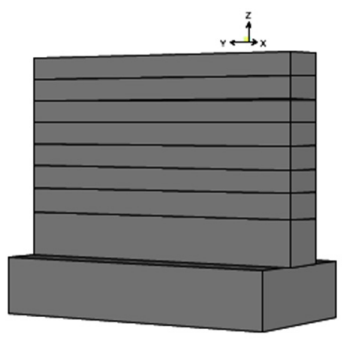

(b)

Figure 6. Finite element model of piers. (a) 0\# pier and 3\# pier. (b) 1\# pier and 2\# pier.

After the finite element model has been established, modal analysis is carried out and the obtained modes of each order are shown in Figure 7. The natural frequency value of each order can also be seen in Table 1.

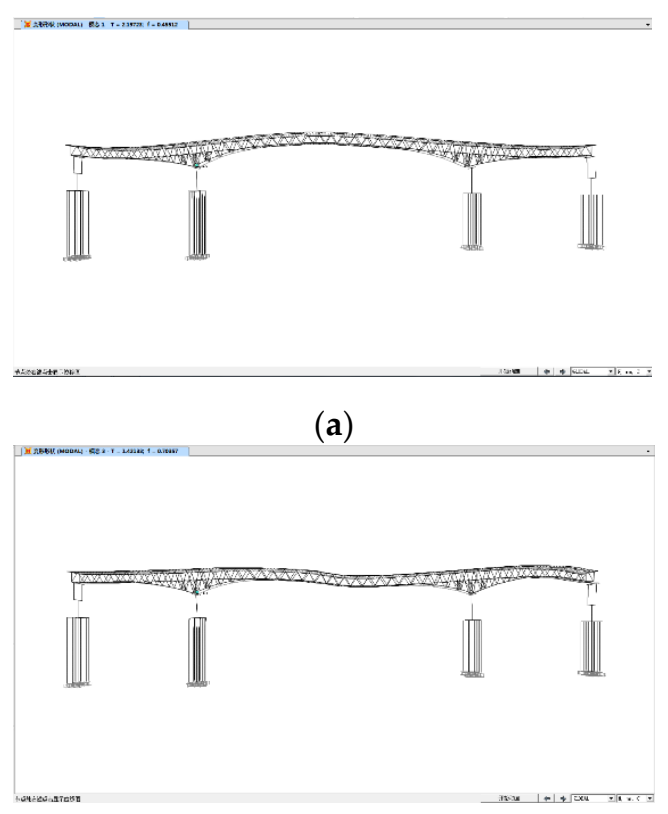

(c)

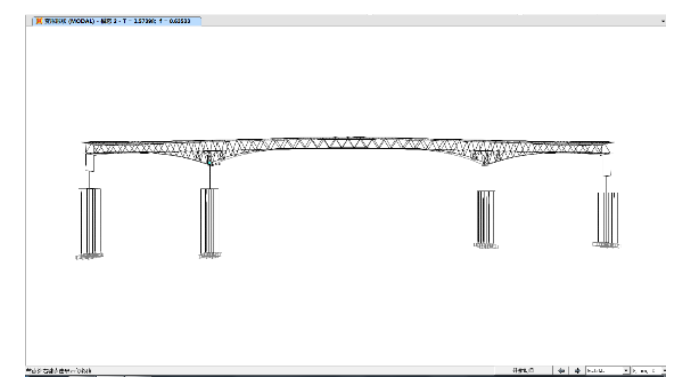

(b)

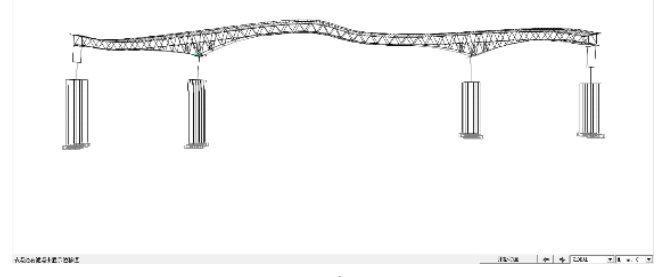

(d)

Figure 7. Cont. 


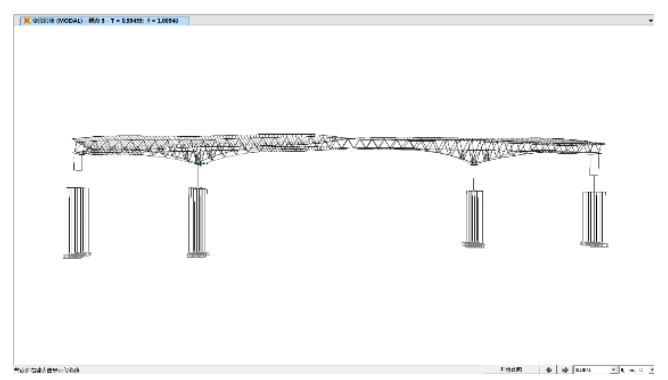

(e)

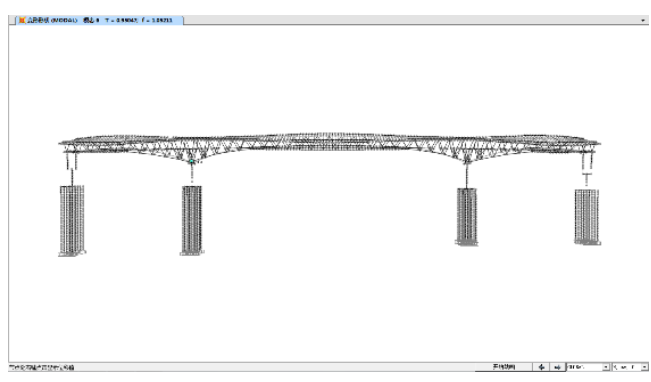

(f)

Figure 7. Front six modes. (a) First mode. (b) Second mode. (c) Third mode. (d) Fourth mode. (e) Fifth mode. (f) Sixth mode.

Table 1. The natural frequency value of each order.

\begin{tabular}{ccc}
\hline Order & Frequency Value & Vibration Characteristics \\
\hline 1 & 0.455 & First-order vertical bending \\
2 & 0.635 & First-order transverse bending \\
3 & 0.704 & Second-order vertical bending \\
4 & 0.944 & Third-order vertical bending \\
5 & 1.006 & First-order torsional deformation \\
6 & 1.052 & Second-order transverse bending \\
7 & 1.308 & Fourth-order vertical bending \\
8 & 1.344 & Second-order torsional deformation \\
9 & 1.405 & Fifth-order vertical bending \\
10 & 1.521 & Third-order transverse bending \\
\hline
\end{tabular}

\subsection{Seismic Dissipation and Isolation Device}

A bridge bearing is the connection and transmission component between the upper beam structure and the lower pier structure. If a bearing system is damaged in an earthquake, the reliability of the beam and pier structure will be directly affected [23-25]. The friction pendulum bearing and viscous damper are used to study the parameters of seismic dissipation and isolation device, and the optimal parameters are obtained to give full details of the performance of the seismic dissipation and isolation device.

\subsubsection{Friction Pendulum Bearing (FPB)}

A friction pendulum bearing (FPB) is composed of an upper base plate, base, ball pendulum, and ball crown lining plate. The upper base plate of the friction pendulum bearing is connected with the upper beam structure of the bridge, and the lower base is directly connected to the pier top. The sliding surface is a curved surface made of stainless steel, and the curvature radius of the stainless-steel curved surface is equal to that of the ball pendulum. Under a vertical force, the compressive stress of the curved surface is uniform. Isolation performance of the friction pendulum bearing (FPB) is related to the curvature radius and the friction coefficient of the sliding surface.

Under an general external force, the friction pendulum bearing (FPB) does not produce an isolation performance. When a horizontal shear force is too large, the limit device of the bearing will be cut off, and the isolation performance of the friction pendulum bearing (FPB) will play out. After an earthquake, the friction pendulum bearing (FPB) can be reset automatically under a dead weight.

The bilinear calculation model of friction pendulum bearing (FPB) is shown in Figure 8. 


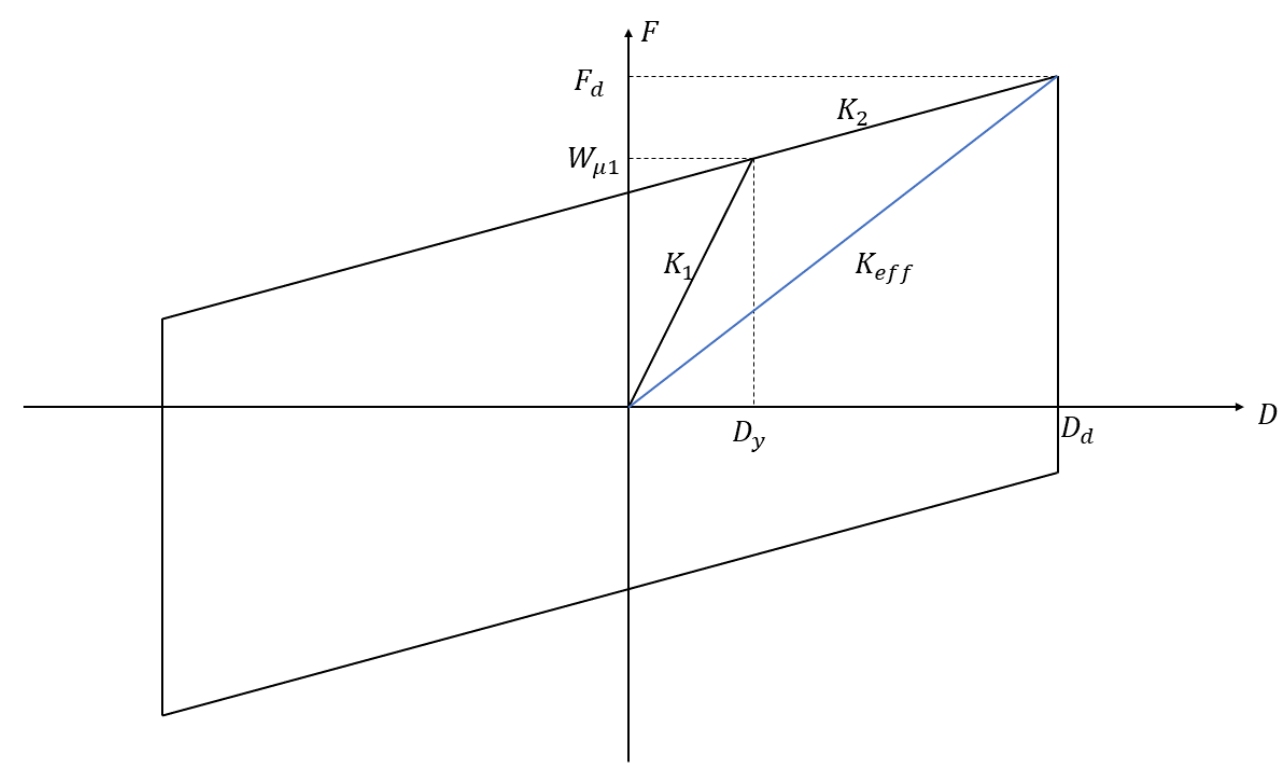

Figure 8. Bilinear calculation model of FPB.

In Figure $8, D_{\mathrm{y}}$ is the yield displacement; $D_{\mathrm{d}}$ is the ultimate displacement; $K_{1}$ is the initial stiffness of FPB; $K_{2}$ is the swing stiffness of FPB.

The equivalent stiffness and equivalent period of the system can be obtained by studying the nonlinear model of the FPB.

$$
\begin{gathered}
K_{e f f}=W / R+\mu * W / D \\
T_{e f f}=2 \pi \sqrt{R * \mathrm{~d} /(d g+R g \mu)} \\
\beta_{e f f}=\frac{2}{\pi} \frac{\mu}{D / R+\mu}
\end{gathered}
$$

where $R$ is the curvature radius and $u$ is the friction coefficient.

\subsubsection{Viscous Damper}

The mechanical model of the damper element is the Maxwell model, and the property analysis of the element mainly includes linear properties and nonlinear properties. For nonlinear properties, dampers are connected with the spring element in parallel; for linear properties, dampers are connected with the spring element in series, and the damping output force is $\mathrm{F}=\mathrm{CV}^{\alpha}$. The performance of a damper is related to damping exponent $\alpha$ and damping coefficient $C$. Parameters should be optimized while taking into account the process and production requirements. The output force of the damper is reduced as much as possible to facilitate joint construction.

\subsection{Selection of Ground Motion}

Ground motion has a strong randomness. According to previous studies, the seismic response of structures is very different, when different seismic waves are input. Therefore, in order to ensure the accuracy of the nonlinear time history analysis results, reasonable seismic waves must be selected [26-30]. When selecting seismic waves, we should first consider three important factors of ground motion: peak ground acceleration (PGA), spectral characteristics, and seismic duration.

Guidelines for Seismic Design of Highway Bridges (JTG/T b02-01-2008) stipulates that three seismic waves conforming to site conditions shall be selected for input. The type of bridge site is class II, and the seismic intensity is a VII degree. In this paper, we consider the degree of an E2 earthquake, which is an earthquake action at the project site with long a recurrence period, defined in Guidelines for Seismic Design of Highway Bridges (JTG/T b02-01-2008). The 
peak ground acceleration (PGA) of the horizontal ground motion under an E2 earthquake is $0.2375 \mathrm{~g}$.

In this paper, Fourier transform and continuous iterative fitting are used to generate artificial seismic waves. The specific methods are as follows:

(1) Referring to Guidelines for Seismic Design of Highway Bridges (JTG/T b02-01-2008), the design response spectrum (expected response spectrum) is determined according to the design parameters, such as the seismic intensity and site classification;

(2) The power spectrum of the artificial seismic wave is approximately calculated according to the expected response spectrum;

(3) The Fourier amplitude spectrum obtained from the power spectrum, plus the random phase, is used to obtain the approximate artificial seismic wave using the inverse fast Fourier transform (IFFT) and the intensity envelope;

(4) The response spectrum of the artificially fitted seismic wave is calculated. The Fourier amplitude spectrum is modified by the ratio of the expected response spectrum to the calculated response spectrum. The artificial seismic wave is regenerated and iterated continuously until the error in the response spectrum at the control frequency point is within the allowable error range.

The three fitting acceleration time history curves under an E2 earthquake can be seen in Figure 9.

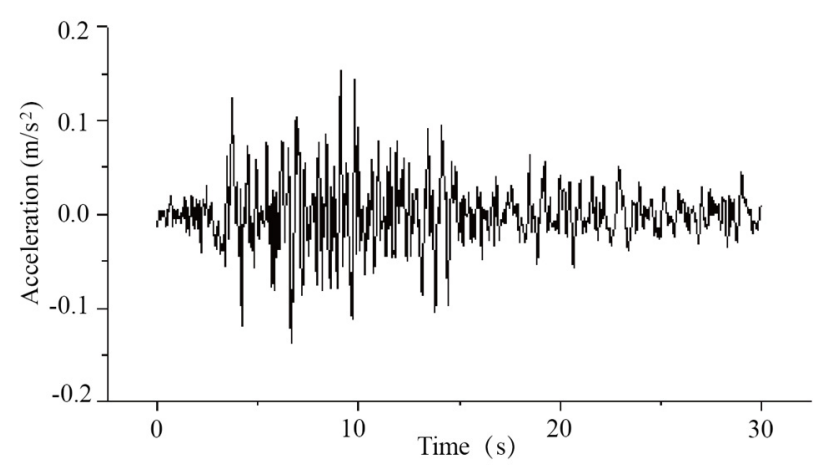

(a)

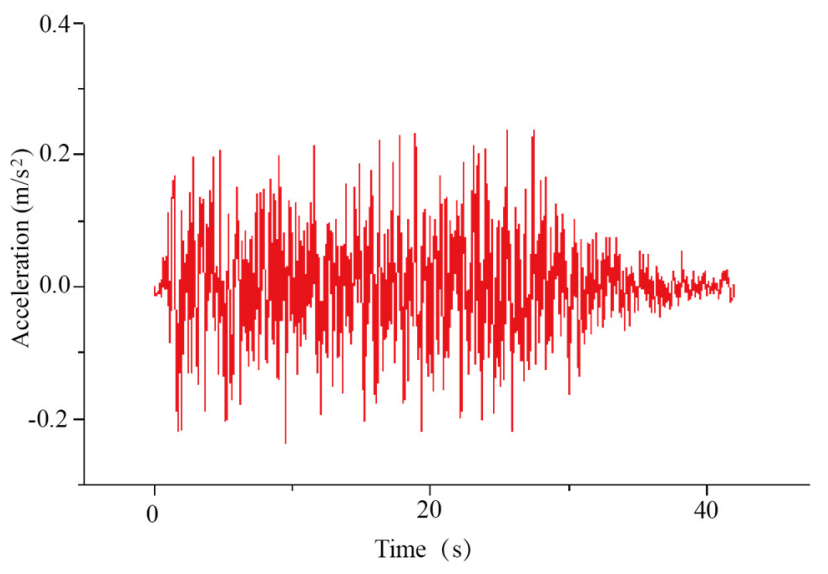

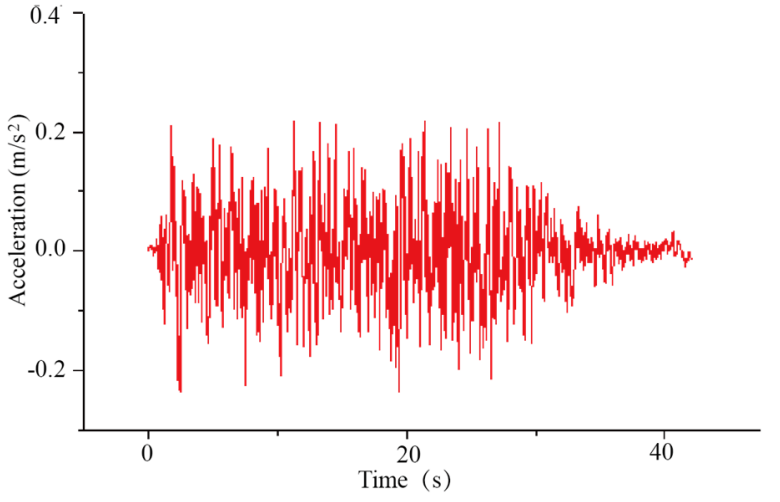

(b)

(c)

Figure 9. Acceleration time history curve of an E2 earthquake. (a) The first acceleration time history curve. (b) The second acceleration time history curve. (c) The third acceleration time history curve. 


\section{Seismic Response of Structures}

\subsection{Seismic Structure}

Through nonlinear time history calculation of the seismic structure, the seismic response of the seismic structure is obtained. The N-M- $\varphi$ curve of the piers was calculated, and the most unfavorable bending moment of each pier, under the most unfavorable axial force, was calculated, as shown in Table 2.

Table 2. Calculation of seismic capacity of pier.

\begin{tabular}{|c|c|c|c|c|c|c|}
\hline \multirow{2}{*}{ Key Section } & \multicolumn{3}{|c|}{$\begin{array}{l}\text { Bending Moment of Longitudinal Bridge Direction } \\
\qquad(\mathrm{kN} \cdot \mathrm{m})\end{array}$} & \multicolumn{3}{|c|}{$\begin{array}{l}\text { Bending Moment of Transverse Bridge Direction } \\
\qquad(\mathrm{kN} \cdot \mathrm{m})\end{array}$} \\
\hline & Force & Resistance & $\mathbf{U}$ & Force & Resistance & $\mathbf{U}$ \\
\hline 0\# pier bottom & $4.86 \times 10^{5}$ & $4.37 \times 10^{5}$ & 0.90 & $6.02 \times 10^{5}$ & $1.92 \times 10^{6}$ & 3.19 \\
\hline 1\# pier bottom & $1.35 \times 10^{6}$ & $8.37 \times 10^{5}$ & 0.62 & $1.16 \times 10^{6}$ & $2.85 \times 10^{6}$ & 2.46 \\
\hline 2\# pier bottom & $2.16 \times 10^{5}$ & $8.36 \times 10^{5}$ & 3.87 & $1.25 \times 10^{6}$ & $2.85 \times 10^{6}$ & 2.28 \\
\hline 3\# pier bottom & $5.33 \times 10^{5}$ & $4.46 \times 10^{5}$ & 0.84 & $6.68 \times 10^{5}$ & $1.92 \times 10^{6}$ & 2.87 \\
\hline
\end{tabular}

Note: $\mathrm{u}=$ resistance/force, representing the ability to resist earthquake.

When the basin seismic bearing is used in a double-deck steel truss structure, the strength-checking calculation of bridge substructure cannot meet the requirements under a longitudinal seismic action, especially for 1\# pier and 3\# pier. Resistance/force is less than 1 , which cannot meet the bending moment demand of the pier and has a large safety reserve under the action of transverse earthquakes.

\subsection{Isolation Structure}

The whole bridge is isolated, that is, 0\# 3\# piers are all equipped with FPBs. Parameters $R$ and $\mu$ of the FPBs are optimized, respectively.

The design of radius $\mathrm{R}$ of the FPB needs to be calculated according to the natural vibration period of the non-seismic isolation structure. Generally, the isolation period is more than two times that of the natural vibration period to determine the radius. Based on the nonlinear time history analysis of the isolation structure, the moment at the bottom of the pier and the relative displacement between piers and beams were obtained under an earthquake action in the longitudinal bridge direction (see Figure 10).

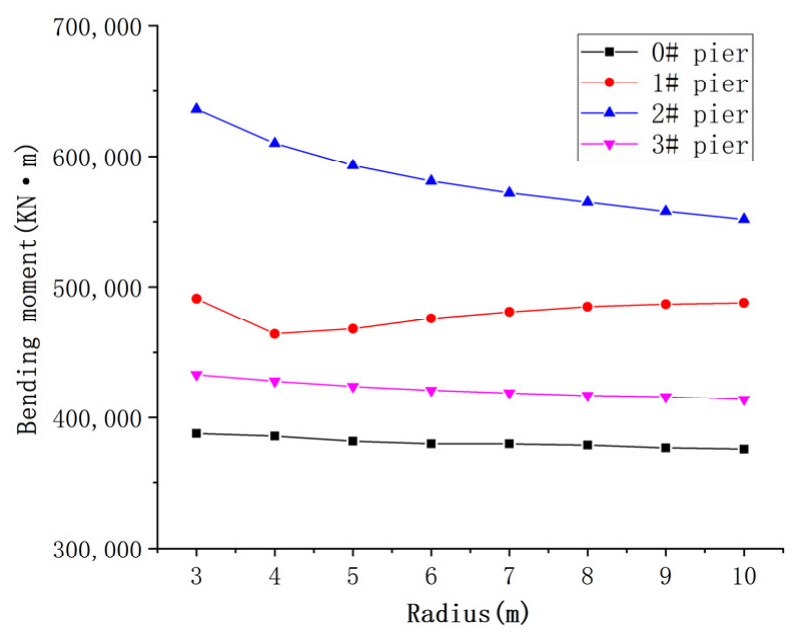

(a)

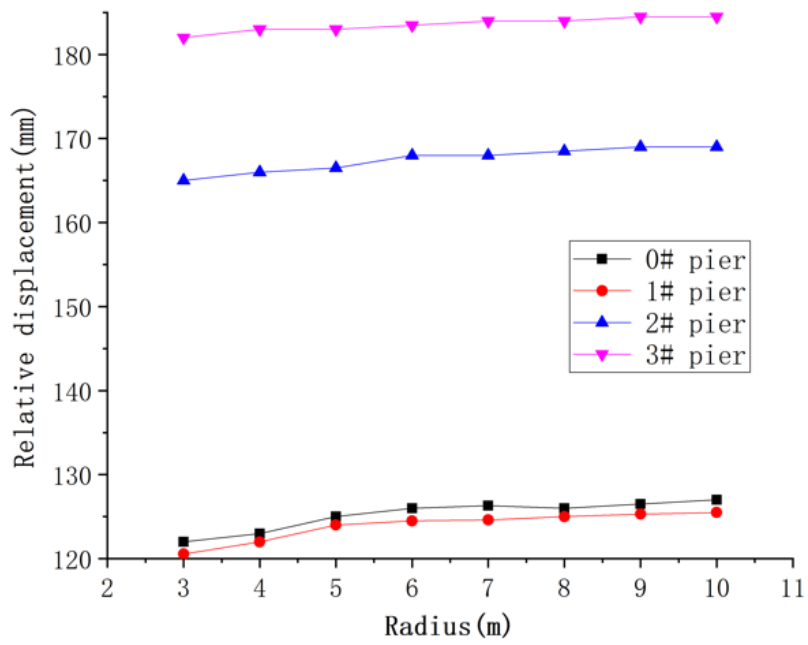

(b)

Figure 10. Seismic response of the longitudinal bridge direction (radius of curvature, R). (a) Bending moment at the bottom of pier (b) Relative displacement between piers and beams. 
Under the action of an E2 earthquake, the bending moment at the bottom of the 1\# pier and 2\# pier decreases with an increase in $\mathrm{R}$, but it does not change much for the $0 \#$ pier and $3 \#$ pier. When $R=3 \mathrm{~m}$, the bending moment at the bottom of the $1 \#$ pier reaches $6.32 \mathrm{E}+5 \mathrm{KN} \cdot \mathrm{m}$, so it is necessary to increase the radius to reduce the bending moment at the bottom of pier; the relative displacement between the piers and beams increases with the increase in $\mathrm{R}$, but the seismic response is relatively similar.

This section studies the isolation effect of the friction coefficient of FPB on the structure. When the $\mathrm{R}$ remains unchanged, friction coefficient $\mu$ is taken as $0.01-0.05$, to calculate the stiffness of FPB, respectively; results are shown in Figure 11.

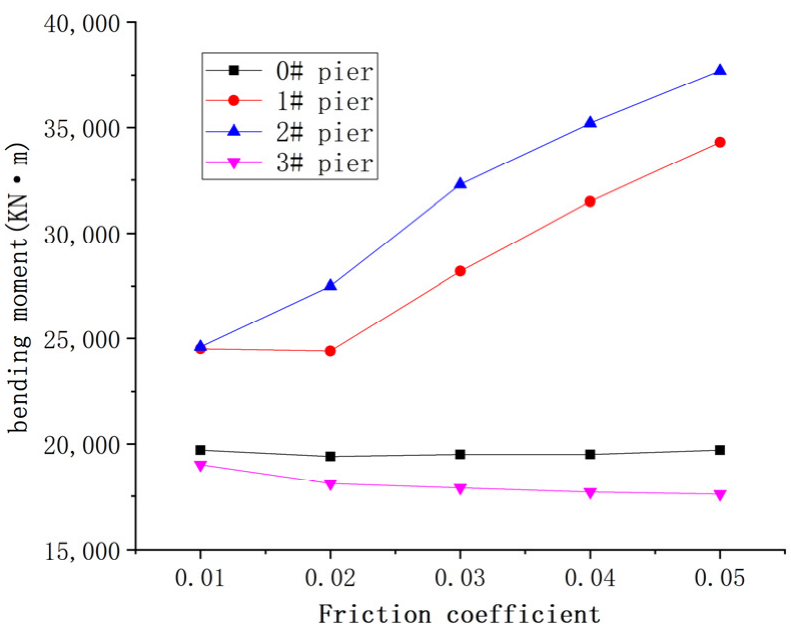

(a)

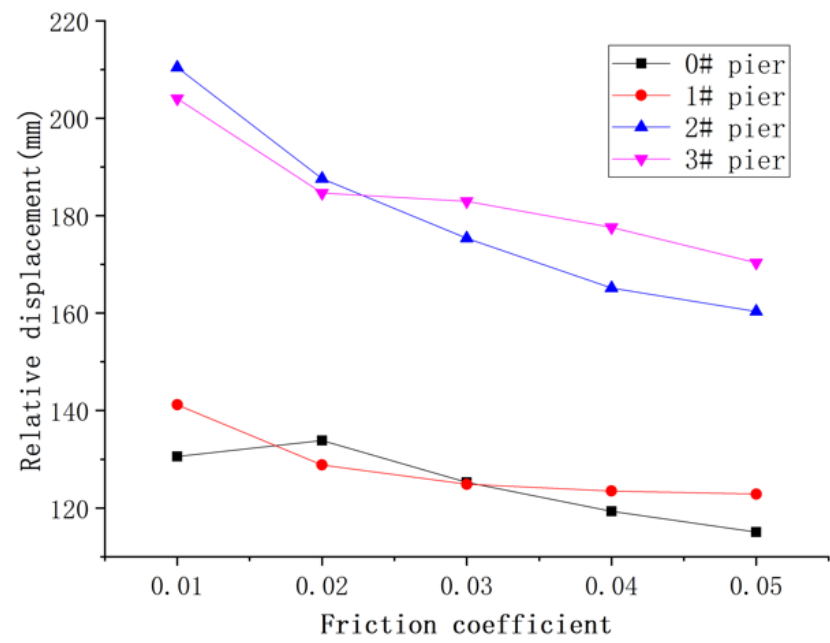

(b)

Figure 11. Seismic response of the longitudinal bridge direction (friction coefficient $\mu$ ). (a) Bending moment at the bottom of pier. (b) Relative displacement between piers and beams.

When the friction coefficient changes from 0.01 to 0.05 , the relative displacement between piers and beams decreases significantly, and the bending moment at the bottom of pier increases gradually. Although the enlargement of the friction coefficient increases the energy dissipation capacity of the bearing and can effectively "grasp" the main beam, the excessive friction force cannot effectively block the transmission of the inertial force between the pier and beam. At that time, the seismic energy is transferred from the main beam to the pier column, resulting in the pier suffering too much internal force, which cannot give full play to the energy dissipation function of the isolation bearing.

Based on research on the variation of the parameters above, $\mathrm{R}$ can be taken as 7.0-10.0 m, and $\mu$ as $0.02-0.03$, which can effectively utilize the isolation performance of FPB. In the study of combined seismic dissipation and isolation (CSDI), the parameters within this range are used to analyze the FPB. The whole bridge isolation scheme can effectively reduce the seismic response. Due to the characteristics of FPB, there will be some residual deformation, which will cause additional stress of the bearing.

\subsection{Combined Seismic Dissipation and Isolation (CSDI) Structure}

Combined seismic dissipation and isolation (CSDI) is adopted, that is, the 0\#, 2\# and $3 \#$ piers are equipped with viscous dampers, and the 1\# pier has an installed FPB with the abovementioned optimized parameters. When the E2 earthquake occurs, the anti-seismic bolt of the fixed pier is cut off, so the FPB and viscous dampers can play a role in CSDI. Now assuming that the damping exponent is 0.5 , and the damping coefficient ranges from 1000 to 10,000, the influence of damping coefficient $C$ on the performance of the damper can be studied. The seismic response of the structure is shown in Figure 12. 


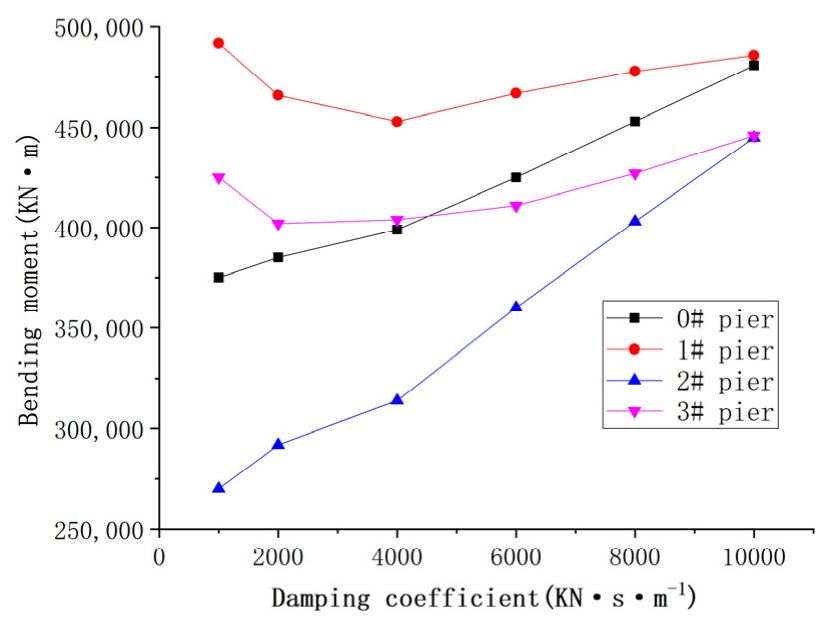

(a)

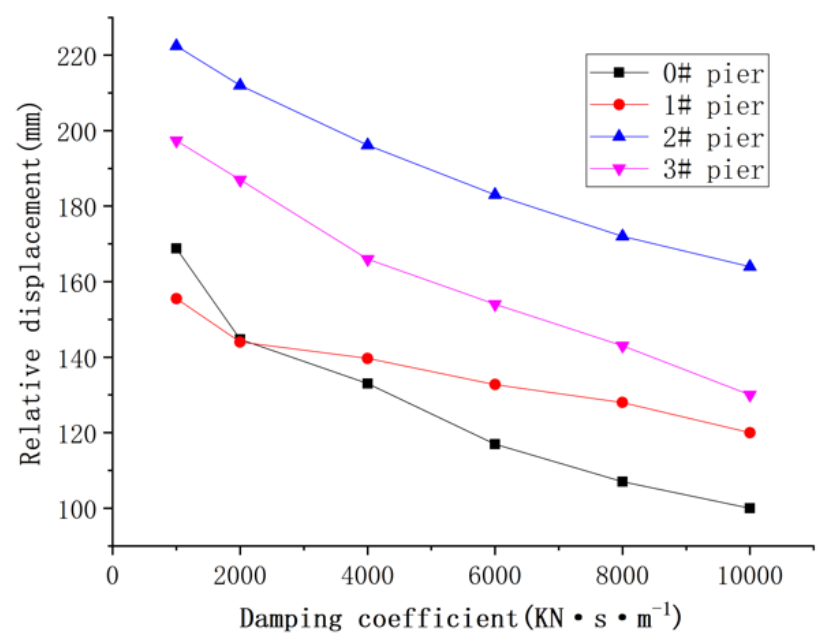

(b)

Figure 12. Seismic response of the longitudinal bridge direction (damping coefficient $C$ ). (a) Bending moment at the bottom of pier. (b) Relative displacement between piers and beams.

It can be seen from Figure 12 that, in the change process of $C$ from 1000 to 10,000, compared with the seismic structure, the relative displacement between the piers and beams can be effectively reduced; however, with an increase in $C$, the output of the damping force will be larger, which will limit the displacement of the upper structure, but is not conducive to dissipating the seismic inertia force; the upper inertia force is transmitted to the lower structure, which increases the bending moment at the pier bottom.

It is proposed to set damping coefficient $C$ as 6000 , and the damping exponent as 0.3 , $0.4,0.6,0.8$, and 1.0. When the damping exponent is 1.0 , the damper is a linear damper. The specific results are shown in Figure 13.

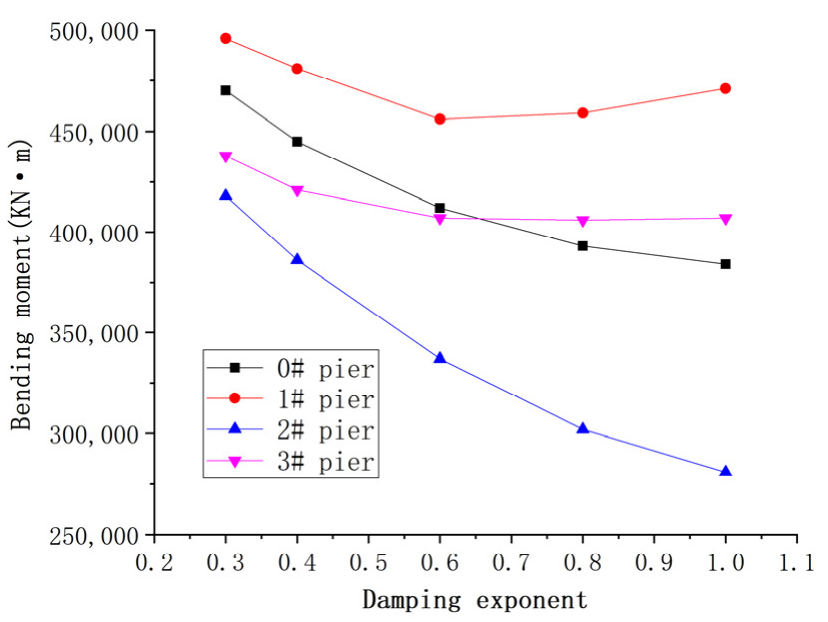

(a)

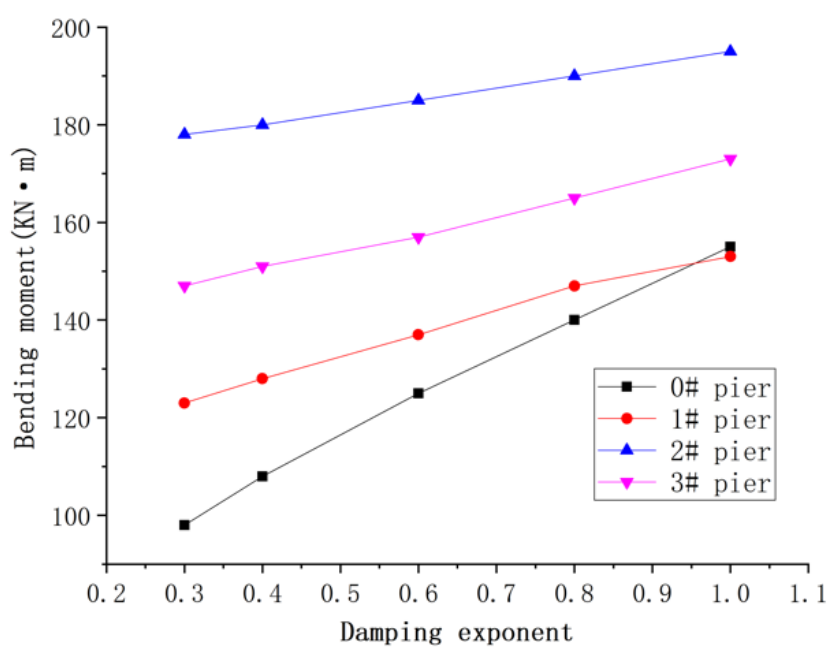

(b)

Figure 13. Seismic response of the longitudinal bridge direction (damping exponent $\alpha$ ). (a) Bending moment at the bottom of pier. (b) Relative displacement between piers and beams.

With the increase in the damping exponent, the bending moment at the bottom of the pier first decreases and then increases; however the bending moment of the pier bottom of the 2\# pier decreases gradually; for the relative displacement between the piers and beams, with an increase in the damping exponent, the displacement response gradually increases. 
Based on the above research rules, the following parameters can be selected: $C=4000-6000$, $\alpha=0.3$.

\subsection{Comparative Analysis of Seismic Response}

It is found that the seismic responses of the pier bottom are within the resistance range of the pier after the isolation scheme is adopted. Figure 14 shows the seismic response time history curve of the pier bottom of the seismic and isolation structure.

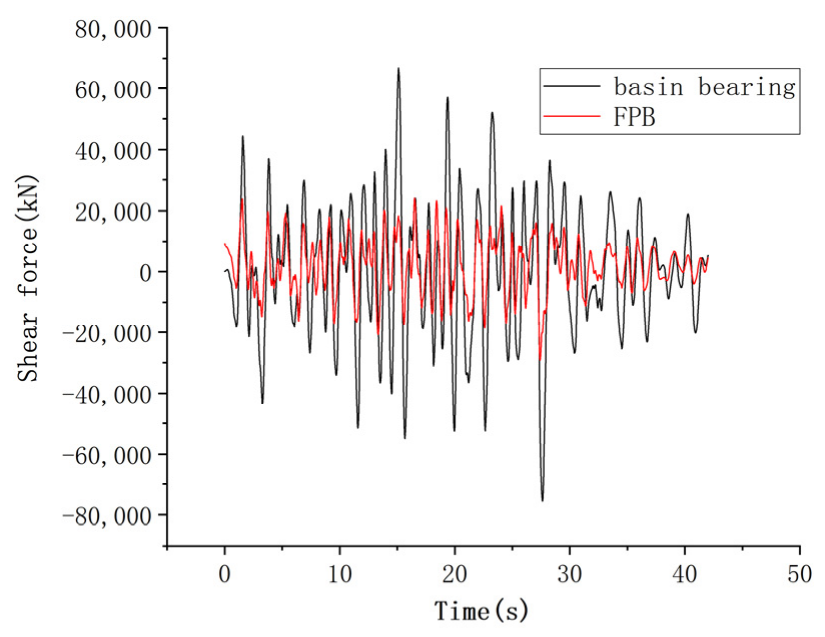

(a)

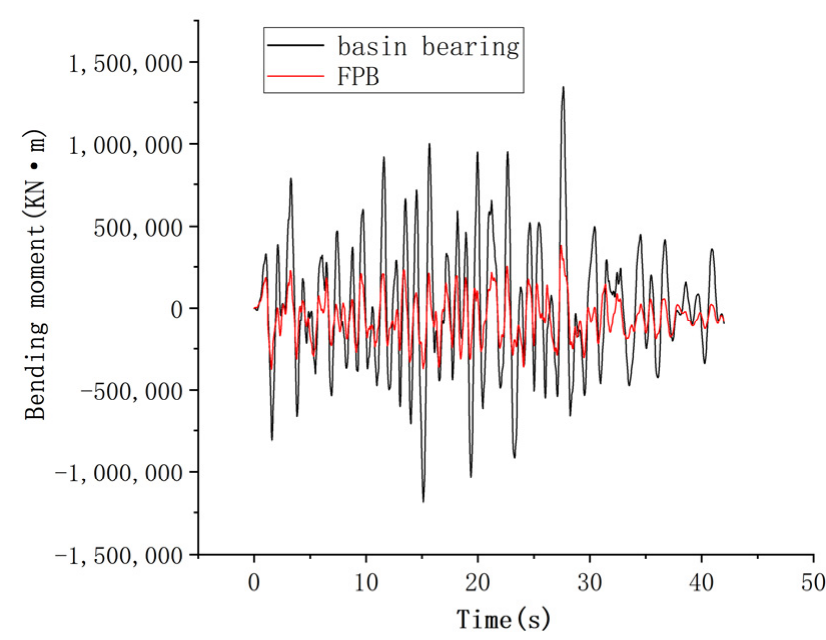

(b)

Figure 14. Seismic and isolation structure of time history curve of the 1\# pier bottom. (a) Shear time history curve of the 1\# pier bottom. (b) Moment time history curve of the 1\# pier bottom.

The isolation response time history curve of the 1\# pier bottom changes obviously when compared with the seismic structure. After using FPB, the time history curve of the pier bottom of the structure is apparently enveloped in the seismic response of the structure. The shape of the time history curve is basically consistent, and the peak point of the isolation structure is evidently smaller than the seismic structure.

It can be seen from Table 3 that the bending moment and the shear force of the $1 \#$ pier are reduced by $65.33 \%$ and $62.67 \%$ compared with the seismic structure after using the isolation scheme, and by $66.22 \%$ and $63.76 \%$ for the CSDI scheme. At the same time, the bending moment and shear force at the bottom of the $2 \#$ pier increased by $174.54 \%$ and $67.88 \%$ compared with the seismic structure when FPB was used. However, the increase in amplitude was small, which is $56.02 \%$ and $15.87 \%$ when CSDI was adopted; this is more conducive to the safety of the pier.

Table 3. Seismic response comparison of substructure.

\begin{tabular}{|c|c|c|c|c|c|c|}
\hline \multirow[b]{2}{*}{$\begin{array}{c}\text { Pier } \\
\text { Number }\end{array}$} & \multicolumn{2}{|c|}{ Seismic Structure } & \multicolumn{2}{|c|}{ Isolation Structure } & \multicolumn{2}{|c|}{ CSDI Structure } \\
\hline & $\begin{array}{l}\text { Bending Moment } \\
\text { in Pier Bottom } \\
(\mathbf{k N} \cdot \mathbf{m})\end{array}$ & $\begin{array}{l}\text { Shear in Pier } \\
\text { Bottom (kN) }\end{array}$ & $\begin{array}{c}\text { Moment } \\
\text { Isolation Ratio }\end{array}$ & $\begin{array}{c}\text { Shear Isolation } \\
\text { Ratio }\end{array}$ & $\begin{array}{c}\text { Moment } \\
\text { Isolation Ratio }\end{array}$ & $\begin{array}{c}\text { Shear Isolation } \\
\text { Ratio }\end{array}$ \\
\hline 0\# & $4.86 \times 10^{5}$ & $2.33 \times 10^{4}$ & $-21.40 \%$ & $-16.65 \%$ & $-15.23 \%$ & $-20.32 \%$ \\
\hline 1\# & $1.35 \times 10^{6}$ & $7.55 \times 10^{4}$ & $-65.33 \%$ & $-62.67 \%$ & $-66.22 \%$ & $-63.76 \%$ \\
\hline $2 \#$ & $2.16 \times 10^{5}$ & $1.92 \times 10^{4}$ & $174.54 \%$ & $67.88 \%$ & $56.02 \%$ & $15.87 \%$ \\
\hline $3 \#$ & $5.33 \times 10^{5}$ & $2.15 \times 10^{4}$ & $-20.45 \%$ & $-16.97 \%$ & $-23.64 \%$ & $-30.58 \%$ \\
\hline
\end{tabular}

It can be seen from Table 4 that the relative displacement between the upper and lower joints decreases after the seismic isolation schemes are adopted, which is conducive to protecting the upper steel truss structure. In the seismic structure, the relative displacement 
reaches $121.41 \mathrm{~mm}$. After using FPB, the relative displacement is reduced to $91.11 \mathrm{~mm}$, which is $24.96 \%$; when CSDI is adopted, the relative displacement is reduced by $42.05 \%$.

Table 4. Seismic response comparison of superstructure.

\begin{tabular}{|c|c|c|c|c|c|}
\hline \multirow[b]{2}{*}{$\begin{array}{l}\text { Node } \\
\text { Number }\end{array}$} & \multirow{2}{*}{$\begin{array}{c}\text { Seismic Structure } \\
\text { Relative } \\
\text { Displacement }(\mathrm{mm})\end{array}$} & \multicolumn{2}{|c|}{ Isolation Structure } & \multicolumn{2}{|c|}{ CSDI Structure } \\
\hline & & $\begin{array}{c}\text { Relative } \\
\text { Displacement }(\mathrm{mm})\end{array}$ & Isolation Rate & $\begin{array}{c}\text { Relative } \\
\text { Displacement (mm) }\end{array}$ & Isolation Rate \\
\hline 1 & 63.13 & 51.44 & $-18.52 \%$ & 48.63 & $-22.97 \%$ \\
\hline 2 & 67.25 & 55.56 & $-17.38 \%$ & 50.36 & $-25.12 \%$ \\
\hline 3 & 73.16 & 60.53 & $-17.26 \%$ & 55.21 & $-24.54 \%$ \\
\hline 4 & 83.94 & 68.09 & $-18.88 \%$ & 60.33 & $-28.13 \%$ \\
\hline 5 & 99.65 & 77.78 & $-21.95 \%$ & 68.33 & $-31.43 \%$ \\
\hline 6 & 121.41 & 91.11 & $-24.96 \%$ & 70.36 & $-42.05 \%$ \\
\hline
\end{tabular}

It can be seen from Figure 15 that the hysteresis curve of the 1\# pier using FPB is close to that of a parallelogram with a large area of hysteresis loop, which effectively exerts its isolation energy dissipation performance. For the hysteresis curve of the 2\# pier using dampers, it is found that the hysteresis loop area is also full. This indicates that the CSDI scheme can effectively exert the isolation performance of FPB and the characteristics of the dampers.

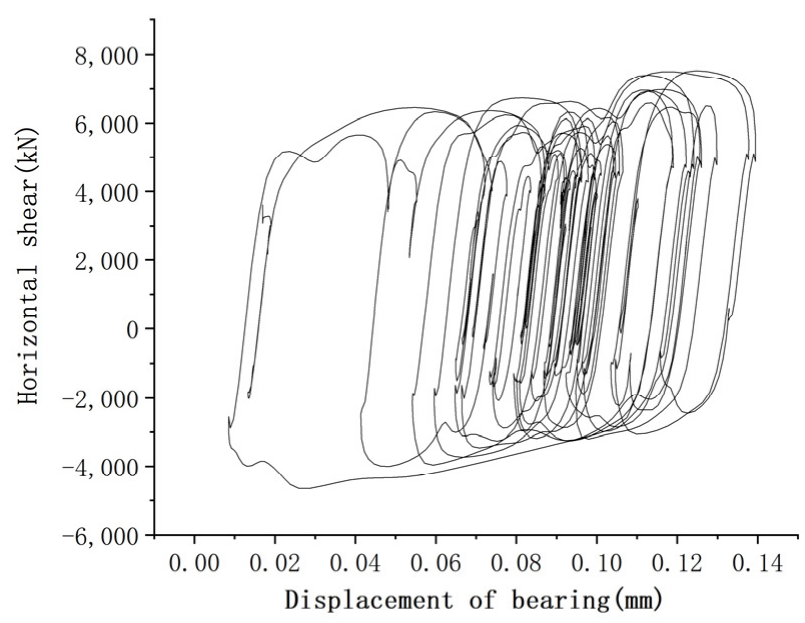

(a)

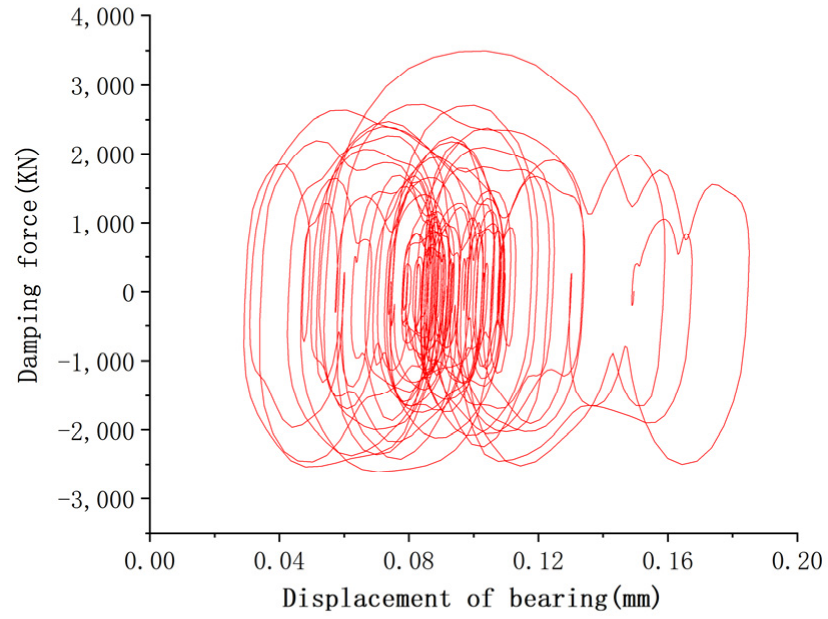

(b)

Figure 15. Hysteresis curve of piers adopting the CSDI scheme. (a) Hysteresis curve of the 1\# pier using FPB. (b) Hysteresis curve of the 2\# pier using dampers.

\section{Conclusions}

Taking a double-deck steel truss continuous girder bridge as the research object, the nonlinear time history analysis method is used to analyze the seismic performance, seismic dissipation, and isolation performance of the bridge structure. The parameters of the FPBs and viscous dampers are analyzed. We can draw the following conclusions:

(1) When isolation is not carried out, the seismic response of the longitudinal bridge direction is mainly borne by the $1 \#$ pier (fixed pier). The superstructure of the bridge is a double-deck steel truss structure, and the continuous beam is not conducive to the safety of the bridge structure.

(2) When FPBs are used in the seismic isolation design of the whole bridge and R and $\mu$ are optimized, the results show that, with the increase in $R$, the seismic response of the pier bottom decreases, but the displacement of the main beam increases; with an increase of $\mu$, the seismic response of the pier bottom increases, but the displacement of the main beam 
decreases. The weight of the superstructure is relatively large, while the layout requires that the $R$ of FPBs be as close as possible, so $R$ can be used at 7-10 m, and $\mu$ is taken as 0.03 , which can be used as the FPB parameters of the bridge.

(3) In the design of CSDI, FPB is used for the 1\# pier and ordinary bearings and viscous dampers are used for other piers. The results show that with the increase of $C$, the seismic response of the pier bottom increases, but the displacement of the main beam decreases; with an increase in $\alpha$, the seismic response of pier bottom decreases, but the displacement of main beam increases. When $C$ is $4000-6000$ and $\alpha$ is 0.3 , the effect of CSDI can be brought into play.

(4) It is found that the time history curves of the shear force and the bending moment at the bottom of the 1\# pier are significantly reduced when FPBs are used for isolation research. When the CSDI design is adopted, the hysteresis loop of the FPBs and dampers is regular and the area is full, which can give full play to the effect of the CSDI device. From the point of view of bearing additional stress, the effect of CSDI is better, which can effectively control the displacement of the bridge superstructure and reduce the relative displacement between piers and beams.

Author Contributions: Y.C.: Conceptualization, Formal analysis, Methodology, Resources, Software, Funding acquisition, Project administration; H.S.: Conceptualization, Data curation, Writingoriginal draft, Methodology, Visualization; Z.F.: Investigation, Validation, Supervision. All authors have read and agreed to the published version of the manuscript.

Funding: This research was funded by Project of Natural Science Foundation of Fujian Province, grant number 2016J05122 and Project of Science and Technology Research of Department of Education of Fujian Province, grant number JA14039, JK2013001.

Conflicts of Interest: The authors declare no conflict of interest.

\section{References}

1. Ugo, M. Seismic Safety Conference-December 2009. J. Homel. Secur. Emerg. Manag. 2011, 6. [CrossRef]

2. Caitlin, M.; McClure, J.; Henrich, L.; Leah, C.; Charleson, A. Reactions to earthquake hazard: Strengthening commercial buildings and voluntary earthquake safety checks on houses in Wellington, New Zealand. Int. J. Disaster Risk Reduction 2018, 28, 465-474.

3. Hing-Ho, T.; Daniell, J.E.; Wenzel, F.; Wilson, J.L. A universal approach for evaluating earthquake safety level based on societal fatality risk. Bull. Earthq. Eng. Off. Publ. Eur. Assoc. Earthq. Eng. 2020, 18, 24-39.

4. Liam, F.W.D.; Ventura Carlos, E.; Guoxi, W. Analysis of ground motions at Treasure Island site during the 1989 Loma Prieta earthquake. Soil Dyn. Earthq. Engineering 1993, 12, 383-390.

5. Şafak, E. Response of a 42-storey steel-frame building to the Ms = 7.1 Loma Prieta earthquake. Eng. Struct. 1993, 15, 403-421. [CrossRef]

6. Boulanger, R.W. Nonlinear Dynamic Analyses of Austrian Dam in the 1989 Loma Prieta Earthquake. J. Geotech. Geoenvironmental Eng. 2019, 145, 05019011. [CrossRef]

7. Li, X.; Wu, S.; Fang, Z. Research on Analysis Method of Seismic Response of Long Span Cable-Stayed Bridge. Appl. Mech. Mater. 2013, 356, 2228-2232. [CrossRef]

8. Calvi, G.M.; Ceresa, P.; Casarotti, C.; Bolognini, D.; Auricchio, F. Effects of axial force variation in the seismic response of bridges isolated with friction pendulum systems. J. Earthq. Eng. 2004, 8, 187-224. [CrossRef]

9. Rebiei, M.; Khoshnoudian, F. Response of multistory friction pendulum base- isolated buildings including the vertical component of earthquakes. Can. J. Civ. Eng. 2011, 38, 1045-1059. [CrossRef]

10. Agrawal, A.K.; Yang, J.N.; He, W.L. Applications of some semiactive control systems to benchmark cable- stayed bridge. J. Struct. Eng. -Asce 2003, 129, 884-894. [CrossRef]

11. Ahmadizadeh, M. On equivalent passive structural control systems for semi-active control using viscous fluid dampers. Struct. Control. Health Monit. 2007, 14, 858-875. [CrossRef]

12. Wong, K.K. Seismic energy analysis of structures with nonlinear fluid viscous dampers- algorithm and numerical verification. Struct. Des. Tall Spec. Build. 2011, 20, 482-496. [CrossRef]

13. Djerouni, S.; Abdeddaim, M.; Elias, S.; Rupakhety, R. Optimum Double Mass Tuned Damper Inerter for Control of Structure Subjected to ground motions. J. Build. Eng. 2021, 44, 103259. [CrossRef]

14. Khalili, M.K.; Karim, B. Softening and hardening tuned mass dampers. Earthq. Struct. 2018, 14, 459-465.

15. Chen, S.R.; Cai, C.S. Coupled vibration control with tuned mass damper for long-span bridges. J. Sound Vib. 2004, 278, 449-459. [CrossRef] 
16. Nam, H.; Fujino, Y.; Warnitchai, P. Optimal tuned mass damper for seismic applications and practical design formulas. Eng. Struct. 2008, 30, 707-715.

17. Chung, L.-L.; Wu, L.-Y.; Huang, H.-H.; Chang, C.-H.; Lien, K.-H. Optimal design theories of tuned mass dampers with nonlinear viscous damping. Earthq. Eng. Eng. Vib. 2009, 8, 547-560. [CrossRef]

18. Kiureghian, A.D. Structural reliability methods for seismic safety assessment: A review. Eng. Struct. 1996, 18, 412-424. [CrossRef]

19. Sfahani, M.G.; Guan, H.; Loo, Y.-C. Seismic Reliability and Risk Assessment of Structures Based on Fragility Analysis-A Review. Adv. Struct. Eng. 2015, 18, 1653-1669. [CrossRef]

20. Hidenao, H.; Marui, T.; Taniguchi, N.; Kayano, S. Restoration of Hanshin Expressway after Kobe/Awaji Earthquake-challenge of 623 days before opening. Cem. Concr. Compos. 2000, 22, 29-38.

21. Burton, H.V.; Gregory, G. Deierlein. Integrating visual damage simulation, virtual inspection, and collapse capacity to evaluate post-earthquake structural safety of buildings. Earthq. Eng. Struct. Dyn. 2018, 47, 294-310. [CrossRef]

22. Goulet, J.A.; Michel, C.; Der Kiureghian, A. Data-driven post-earthquake rapid structural safety assessment. Earthq. Eng. Struct. Dyn. 2015, 44, 549-562. [CrossRef]

23. Kim, S.-H.; Mha, H.-S.; Lee, S.-W. Effects of bearing damage upon seismic behaviors of a multi-span girder bridge. Eng. Struct. 2006, 28, 1071-1080. [CrossRef]

24. Murat, D.; Michel, B. Energy approach to sliding of single-span simply supported slab-on-girder steel highway bridges with damaged bearings. Earthq. Eng. Struct. Dyn. 1995, 24, 395-409.

25. Yahya, N.A.; Dhanasekar, M.; Hamid, H.A. Localised failure mechanism of concrete pedestals under bridge bearing. Aust. J. Civ. Eng. 2020, 18, 164-175. [CrossRef]

26. Ghodrati, G.; Amiri, F. Manouchehri Dana. Introduction of the most suitable parameter for selection of critical earthquake. Comput. Struct. 2005, 83, 613-626.

27. Bozbey, I.; Gundogdu, O. A methodology to select seismic coefficients based on upper bound "Newmark" displacements using earthquake records from Turkey. Soil Dyn. Earthq. Eng. 2011, 31, 440-451. [CrossRef]

28. Zhao, Y.; Li, Y.; Zhang, Y.; Kennedy, D. Nonstationary seismic response analysis of long-span structures by frequency domain method considering wave passage effect. Soil Dyn. Earthq. Eng. 2018, 109, 1-9. [CrossRef]

29. Álamo, G.M.; Padrón, L.A.; Aznárez, J.J.; Maeso, O. Structure-soil-structure interaction effects on the dynamic response of piled structures under obliquely incident seismic shear waves. Soil Dyn. Earthq. Eng. 2015, 78, 142-153. [CrossRef]

30. Pnevmatikos, N.; Sentzas, V. Preliminary estimation of response of curved bridges subjected to earthquake loading. J. Civ. Eng. Archit. 2012, 6, 1530-1535. 